\title{
The analysis of the Basic Advantages and Constraints of Collaborative Innovation Development of Small and Micro Enterprises in Jilin Province Chunyan Gong
}

\author{
College of Humanities and Sciences of Northeast Normal University, Changchun, \\ Jilin Province 130117, China \\ 562499369@qq.com
}

Keywords: Small and micro enterprises; Synergy innovation; Basic advantages and constraints

\begin{abstract}
As the economy enters a "new normal", sustained healthy development of small and micro enterprises has been promoted as China's national strategy. However, there are many small and micro enterprises still keeping their traditional development mode. It is hard for them to raise money and make profit and they are trapped into dilemma of low-level development and weak innovation capability due to their closeness and refusal to interact with the external world as well as lack of awareness to collaborate innovation and keeping warm. This seriously restricts the development of these enterprises. Therefore, the paper took small and micro enterprises as the research objects to analyze the basic advantages that push the synergy innovation development among these enterprises and restricted factors that hinders the development, hoping to provide some effective suggestions to accelerate the synergy innovation development of small and micro enterprises in Jilin Province.
\end{abstract}

\section{Introduction}

In Jilin Province is one of Chinese renowned heavy industrial base. Starting the business relatively late, most of small and micro enterprises here are still started late, most of them are still in the infancy or the period of growing. The whole economy system, which is still dominated by the grass-root level, shows the features of large-number, labor-intensive, uneven development and distribution, short life cycle and so on. Independent innovation awareness of small and micro enterprises in Jilin Province is weak. They also do not strong motivation to carry on independent innovation, in result of which they are still far behind the national level. Thus, the paper aims to provide effective methods to improve independent innovation ability of small and medium enterprises in Jilin Province by synergy innovation.

\section{An Overview for Related Theories}

The Definition of Small and Micro Enterprises. The phrase "small and micro enterprises" was firstly put forward by Chinese economists Lang Xianping in 2011. Circular on printing and distributing the standards for small and medium enterprises(MIIT GLCs [2011] No.300), which was jointly released by Chinese MIT, National Bureau of Statistics, National Development and Reform Commission and Treasury Department in 2011, enterprises that can be defined as small and micro enterprises have been specified: in scientific industrial sectors including the industry of Electronic information, Bio-engineering, new material, new energy and so on, enterprises with 10-100 employees are defines as small enterprises and enterprises with less than 10 employees are defined as micro enterprises. With the advantage of large-number and wide sectors coverage, small and micro enterprise group has become the most important force in global economy activities.

Connotation of Synergy Innovation of Small and Micro Enterprises. Synergy innovation first originated from Synergetics raised by a Professor Hermann Haken from German in 1972. He define the synergy as following: Multi subsystems work together to form an unified integer. Based on Xiong Bite's innovation theory, Hermann Haken's Synergy theory, Marshall's Scope economic theory, Potter's diamond theory, krugman's theory of industrial clustering, the author take different perspectives to innovatively present the meaning of Synergy innovation of enterprises as 
following: it means that different plural subjects related to enterprises' innovation from both internal and external collaborate with each other to achieve the non-linear amplification of effect : $1+1+1>3$.

\section{Basic Situation}

The Atmosphere of Collaborate Innovation is Forming with the Increasing Development of Science and Technology. Since China announced its eleventh Five-year Plan, Jilin Province has invested more in science and technology resources. Based on Statistical yearbook of Jilin Province in 2016 and Statistical bulletin of national economic and social development of Jilin Province in 2016, the author made a detailed statistical description on the Development of science and technology in Jilin Province from 2007 -2016, as shown in Table 1.

Table 1 Development of science and technology in Jilin Province from 2007 -2016

\begin{tabular}{|c|c|c|c|c|c|c|c|}
\hline Index & $\begin{array}{c}\text { R\& D } \\
\text { Expenditure }\end{array}$ & $\begin{array}{c}\text { Percentage } \\
\text { R\& D } \\
\text { in GDP }\end{array}$ & $\begin{array}{l}\text { Total } \\
\text { achieve- } \\
\text { ments }\end{array}$ & $\begin{array}{c}\text { Tech } \\
\text { Appli- } \\
\text { cation }\end{array}$ & $\begin{array}{c}\text { Turnover of } \\
\text { technology } \\
\text { market }\end{array}$ & $\begin{array}{c}\text { Patent } \\
\text { applica } \\
\text {-tion }\end{array}$ & $\begin{array}{c}\text { Patent } \\
\text { acceptance }\end{array}$ \\
\hline unit & Million RMB & $\%$ & ITEM & ITEM & Billion RMB & piece & piece \\
\hline $\mathbf{2 0 0 7}$ & 508658 & 0.96 & 515 & 448 & 17.5 & 5251 & 2855 \\
\hline $\mathbf{2 0 0 8}$ & 632618 & 0.87 & 413 & 357 & 19.8 & 5536 & 2984 \\
\hline $\mathbf{2 0 0 9}$ & 813602 & 1.12 & 510 & 441 & 19.8 & 5934 & 3274 \\
\hline $\mathbf{2 0 1 0}$ & 758005 & 0.87 & 487 & 398 & 18.8 & 6445 & 4343 \\
\hline $\mathbf{2 0 1 1}$ & 934767 & 0.88 & 500 & 419 & 26.3 & 8196 & 4920 \\
\hline $\mathbf{2 0 1 2}$ & 1098000 & 0.92 & 606 & 480 & 25.1 & 9171 & 5923 \\
\hline $\mathbf{2 0 1 3}$ & 1182863 & 0.91 & 680 & 577 & 34.7 & 10751 & 6219 \\
\hline $\mathbf{2 0 1 4}$ & 1307243 & 0.95 & 696 & 592 & 28.2 & 11933 & 6696 \\
\hline $\mathbf{2 0 1 5}$ & 1414089 & 1.01 & 816 & 639 & 26.4 & 14800 & 8878 \\
\hline $\mathbf{2 0 1 6}$ & -- & $\begin{array}{c}1.09 \\
\text { (evaluation) }\end{array}$ & $\begin{array}{c}\text { (evaluatio } \\
\text { n) }\end{array}$ & 717 & 115.38 & 18922 & 9995 \\
\hline
\end{tabular}

From the table above, R\&D expenditure in 2015 has increased by $178 \%$ compared with that in 2007; compared with 2007, turn volume of technology in 2016 has increased by 559\%; the quantity of authorized patent application has increased by $260 \%$; the quantity of grant patent application has increased by $250 \%$. This improvement has made a sound atmosphere to promote the development of collaborative innovation of small and micro enterprises in Jilin Province.

With More and More Perfect Experimental Condition for Science and Technology, Enterprises are also Improving their Ability of Synergy Innovation. Nowadays, there are 137 scientific research institutions and 266 Enterprise scientific research institutions in Jilin Province, among which there are 12 key state laboratories, 5 National Engineering Technology Research Centers, 59 Provincial Key Laboratories, 118 Provincial Science and Technology Innovation Centers(Engineering Technology Research Center) and 3 Public service platforms. Currently, there has been more than 30 National and ministerial key experiments covering the fields including optoelectronics, automobile dynamic simulation, applied optics and super hard material as well as corresponding open laboratories and 46 middle-size bases. There are also multiple city-level R\&D institutions like Changchun Institute of Optics and Fine Mechanics and of applied chemistry as well as more than 40 institutions of higher learning including Jilin University and Northeast Normal University. Moreover, the numbers of scientists, engineers and college students in ten thousand people all rank front row in the country. With apparent advantages in higher education, our province has grasped key techniques in some fields. For example, based on theoretical analysis in the field of Polymeric functional materials and life sciences, we have made some practical 
achievement. Manufacturing technology to produce high-speed track Passenger Car has been the first in the world. Non-food biomass technology has been in the forefront of the world. Jilin's Wet Method Producing Techniques of fuel ethanol is the pioneer method in the world. All these resources have created a soft-environment for the Small and micro enterprises in Jilin Province to improve their ability to develop collaborative innovation.

As the High-Tech Special Industrial Parks Become More and More Mature, Carrier of Synergy Carriers Begin to Take its Shape. Currently, nine cities and states in Jilin province has built their own characteristic industrial parks to make full use of their local development advantages, led by the Changchun and Jilin. These industrial parks begin to take the shapes and gradually become the leading force in the development of synergy innovation of small and micro enterprises. By the end of 2016, there has been 96 characteristic industrial parks and 5431 settled enterprises in Jilin Province. The main distribution of these different characteristic industrial parks has been shown as following.

Table 2 Distribution of characteristic industrial parks in Jilin Province

\begin{tabular}{|c|l|}
\hline the City & \multicolumn{1}{|c|}{ Distribution of characteristic industrial parks } \\
\hline Changchun & $\begin{array}{l}\text { Automobile and parts, track passenger car, agricultural machinery, } \\
\text { maize deep processing, optoelectronics and optoelectronic information, } \\
\text { Modern Chinese Medicine, Leather processing, Deer products } \\
\text { processing, software development and so on }\end{array}$ \\
\hline Jilin & $\begin{array}{l}\text { Organic chemistry and Fine chemical industry, new materials, food } \\
\text { processing, chemical fiber textile industry, Building material Fine steel } \\
\text { and furnace charge }\end{array}$ \\
\hline Siping & $\begin{array}{l}\text { Heat exchanger, agricultural and sideline products processing, glass and } \\
\text { glassware, Deer products deep processing }\end{array}$ \\
\hline Liaoyuan & Socks industry, Leather products, Pharmaceuticals \\
\hline Tonghua & $\begin{array}{l}\text { Quality Steel Products, medicine ,Petroleum Machinery ,Nut } \\
\text { food,Forest products processing }\end{array}$ \\
\hline Baishan & $\begin{array}{l}\text { Mineral water, Forest products processing, Ginseng processing, } \\
\text { Diatomite deep processing, coal deep-processing }\end{array}$ \\
\hline Baicheng & $\begin{array}{l}\text { Agricultural grains deep processing, Power equipment manufacturing, } \\
\text { Building material }\end{array}$ \\
\hline Baicheng & $\begin{array}{l}\text { petrochemical industry, Petroleum drilling machinery, food deep } \\
\text { processing }\end{array}$ \\
\hline Yanbian & $\begin{array}{l}\text { Forest products processing, Nonferrous metal mining and processing, } \\
\text { medicine, Ginseng products, software development }\end{array}$ \\
\hline
\end{tabular}

It can be seen from the table above that industrial agglomerations have begun to take the shape in various industry, which creates a sound environment for synergy innovation of small and micro enterprises in Jilin Province.

Wide Coverage of Informationization of Small and Micro Enterprises Provide Information Resources Guarantee of Synergy Innovation. According to experience at home and abroad, the development speed of enterprise informationization has a profound impact on synergy innovation of small and micro enterprises, based on which Jilin Governments has started to promote the development of enterprise informationization since 2007. The implementation of "1155 project" takes three to five million yuan from enterprises special funds to support enterprise informationization construction. In 2015, Jilin focus on the development of internet economy and information consumption to accelerate the construction of "Smart Jilin". By the end of 2016, more than $90 \%$ individual enterprises in Jilin Province have finished their pre-construction work, as shown in Fig.1. Moreover, nearly 4000 small and medium-sized enterprises have started do their business on Alibaba 1688 and more than 6400 enterprises have joined into Baidu Marketing System. This advantage provides the information technology platform for the development of synergy 
innovation of small and micro enterprises in Jilin Province.

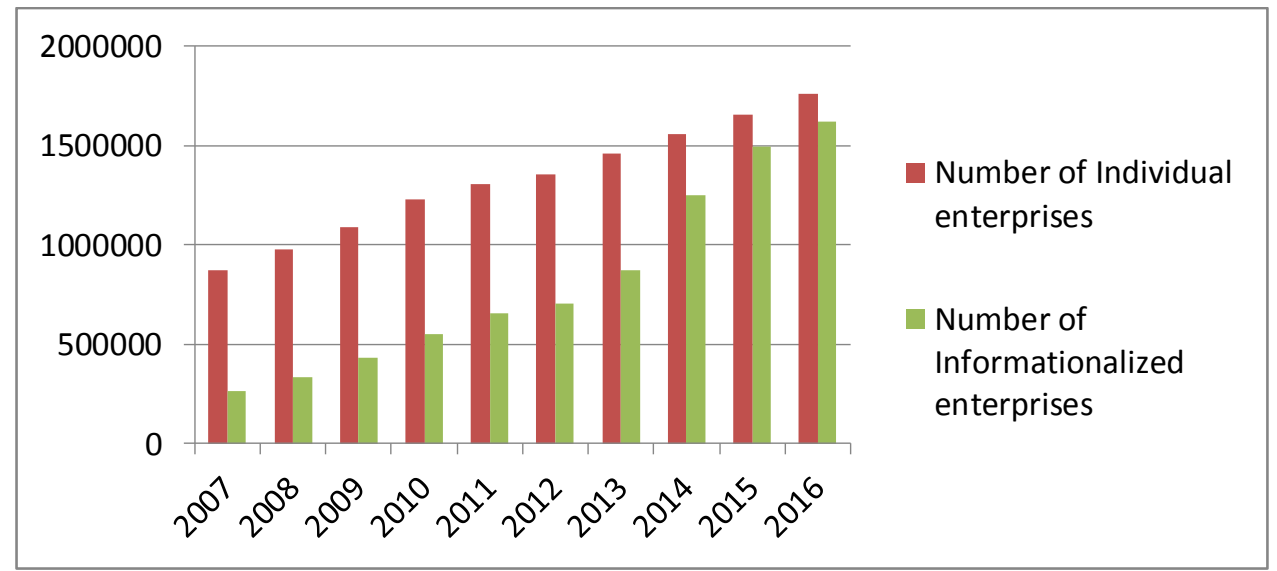

Fig. 1 Investigation on informationization of individual enterprises in Jilin Province

\section{Analysis of Constraints that Hinders the Development of Synergy Innovation of Small and Micro Enterprises in Jilin Province}

To further analyze deep reasons that restricted the development of synergy innovation of small and micro enterprises in Jilin Province, the authors delivered 250 questionnaire to Small and micro enterprises in Jilin Province and collected 226 validated questionnaires. Regions investigated and the industry distribution in these regions have shown in Fig. 2 and Fig. 3.

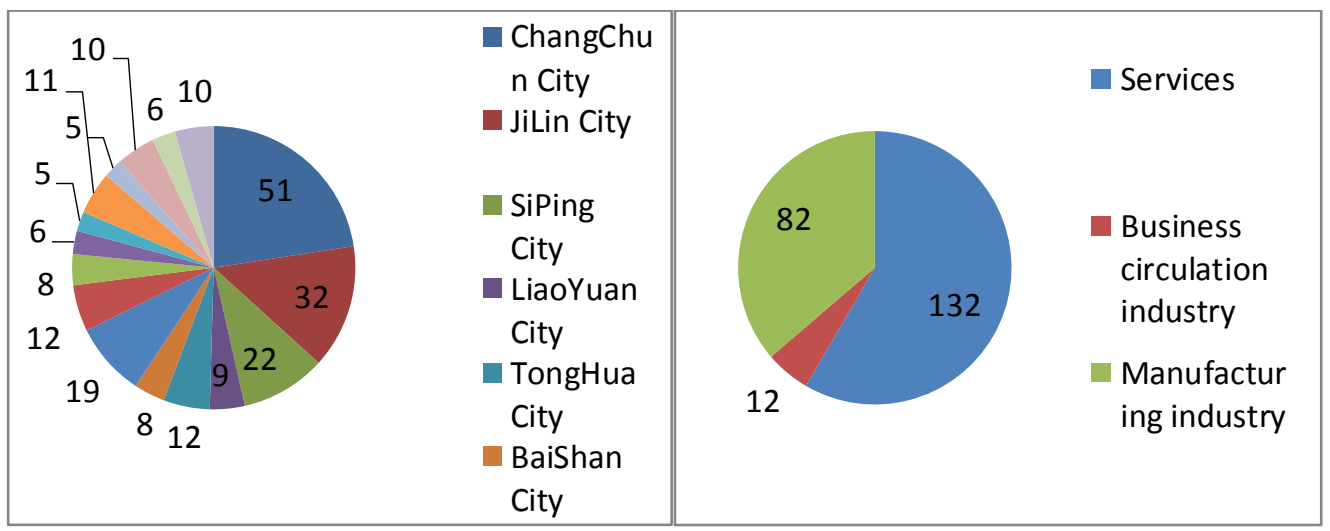

Fig.2 Regional distribution

Fig.3 Distribution of industry

According to the statistic graphs above: samples mainly are regions in Changchun city and covers sixteen cities including Jilin, Siping, Tonghua, Baicheng, Jiutai and etc. with services and manufacturing as the dominant industry in nearly 20 industries involving in manufacturing, wholesale retailing and catering tourism. Though the sample can not represents all Small and micro enterprises in Jilin Province, they can provide us with valuable information which can be referred. Based on the questionnaire results and related data and information that we got previously, the authors deeply analyzed the factors restricting the development of synergy innovation of small and micro enterprises in Jilin Province from macro, medium and micro level.

Analysis of Macro Constraints. Analysis of macro-factors is to analyze the factors at a national level. It can provide further support the development of synergy innovation of small and micro enterprises in Jilin Province. Based on results of Questionnaire investigation and field research, it can be concluded that the first three macro constraints are, in this order, support of national preferential policies, financial and taxation support, protection of intellectual property right. The impacts of these constraints have shown in Fig.4. 


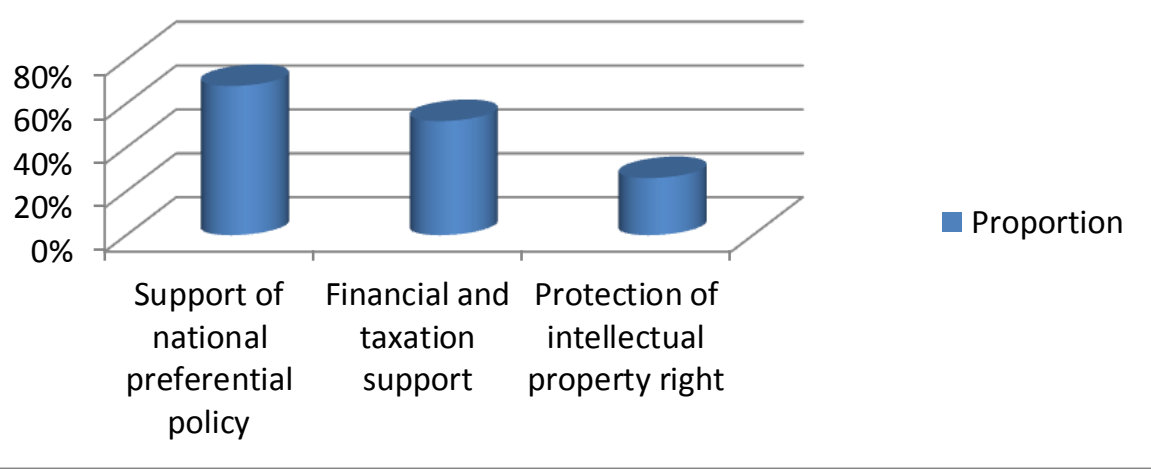

Fig. 4 Distribution of Attention that Small and medium-sized enterprises surveyed in Jilin Province have paid to marco factors

As shown in figure above, among all surveyed small and micro enterprises in Jilin Province, $69 \%$ enterprises concern about the support of national preferential policies; $53 \%$ concern about financial and taxation support and $27 \%$ concern about the protection of intellectual property right.

Analysis of Middle-Level Constraints. Analysis of Middle -level constraints is to analyze constrains at a regional level. It can further promote the development of synergy innovation of small and micro enterprises. Based on results of questionnaire investigation and field research, it can be concluded that the first four middle-level constraints are, in this order, Entrepreneur training support; bonding strength of industry, school and institutes; construction of diversified financing channel; information sharing among industries. Impacts of these four constraint have shown in Fig.5

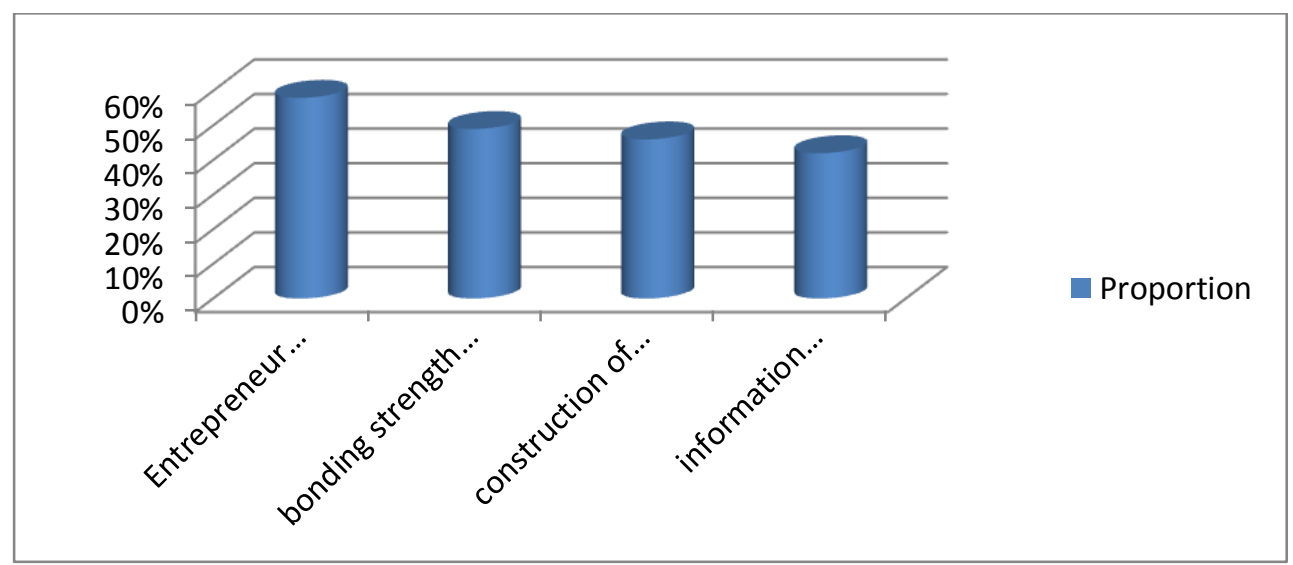

Fig. 5 Distribution of Attention that Small and medium-sized enterprises surveyed in Jilin Province have paid to middle-level factors

As shown in figure above, among all surveyed small and micro enterprises in Jilin Province, $63 \%$ enterprises concern about Entrepreneur training support; 53\% concern about bonding strength of industry, school and institutes; $52 \%$ concern about construction of diversified financing channel and $48 \%$ concern about information sharing among industries.

Analysis of Micro Constraints. Analysis of micro constraints is to analyze constraints at the enterprise level. It can accelerate the development of synergy innovation of small and micro enterprises. Based on results of questionnaire investigation and field research, among all small and micro enterprises surveyed in Jilin Province, more than 85\% enterprises think they haven't achieved perfection in multiple aspects including corporate cultural development, marketing mix strategy, management of the knowledge-typed employees, internal control and so on, which has seriously restricted the process of accelerating the synergy innovation development. These four micro constraints have different impact on different enterprises in their independent innovation activities. 


\section{Suggestions to Promote the Synergy Innovation Development of Small and Micro Enterprises in Jilin Province}

Base on Macroscopic Aspect to Make Full use of its Supporting. First of all, the country should guide governments at all levels to build organization covering province, city, county, village to provide comprehensive services for small and micro enterprises to develop public welfare and supportive service programs and meanwhile, to improve service network coverage and enhance the radiation effect of service resources. Secondly, leading department at national level should be set up to manage these small and micro enterprises to supervise and rate their financial and credit status to finish the top-level design. At last, more attention should be paid to the protection of intellectual property right, expand the scope of the advertising audience through information channel to raise enterprises' awareness to protect intellectual property right.

Base on Middle-Level Aspects to Make Full use of its Thrusting. For the first of all, the Provincial Government should lead to build entrepreneur training mechanism to accelerate the construction of private entrepreneur team and improve their abilities, like "three ones" and "1551" projects mentioned above, which have appear to be working; secondly, with the visible hand, the government should establish New Industrial Technology Innovation Consortiums to provide fund and policy support for their achievement commercialization thus to make it less risky for the enterprises; finally, the government should actively encourage Policy banks and Joint-stock banks to set up finance service specifically for small and micro enterprises and refine the classification of financing category into, like Cluster financing, venture financing and so on, to develop financial products suitable for enterprises on different development stages to establish diversified channel for these enterprises to raise capital.

Base on Micro Aspect to Enhance Its Tension Effect. For the first of all, enterprises should establish culture that encourage enterprises innovation. Small and micro enterprises in Jilin Province always follow "boss culture", which made it hard for employees to perform their creativity well. Thus, Small and micro enterprises in Jilin Province should foster the core value of " humanism management" and embody three "emphasis" in the construction of innovation culture, for example, emphasis on democratic participation; emphasis on Equal cooperation and proper authorization; secondly, enterprises should set up the consumer-oriented marketing idea. Enterprises should grasp consumers' psychology based on the marketing to provide them with directed services. For example, adopt experience-style marketing strategy, which will win consumers' trust with the products quality and open their heart with price advantage.

\section{Summary}

The objective of this paper is to promote the innovative development of small and micro enterprises in Jilin Province. Based on the methodology of data analysis, the main constrains factors of innovative development for the researched firms were determined. As a result, conclusions and recommendations are put forward. Based on macroscopic aspect, governments at all levels should build service organization to offer comprehensive services for small and micro enterprises via welfare and supportive service programs and meanwhile to improve service network coverage and enhance the radiation effect of service resources. In addition, more attention should be paid to the protection of intellectual property right. At middle-level aspects, government should lead to build entrepreneur training mechanism to accelerate the construction of private entrepreneur team and improve their innovation abilities, and establish policy support and financial channel. On micro aspects, enterprises should establish innovative culture.

\section{Acknowledgments}

The paper is the achievements of the " $13^{\text {th }}$ Five" Social Science Fund of the Education Department of Jilin Province, with contract number of JJKH20170982SK . 


\section{References}

[1] Wang Xiao, Pu Jia, Research on Synergy Innovation Strategy of small and micro enterprise under the open innovation environment, J of Chinese business theory,2017, No 2.

[2] Yu Weizhen, Mechanism of Synergy Innovation driving the growth of small and micro enterprise: On the Foundation of I-P-O analysis model, J of Technology and Industry,2016,No 2,p130-133

[3] Lu Yong, Attention should be paid to synergy innovation of small and micro enterprises under the new normal, J of JiangNan Forum,2016,No 2,p24-26.

[4] Zhao Dumin, Research on synergy development of small and medium sized private enterprises, J of Journal of HuangHe Science and Technology College,2016,No 9,p46-53.

[5] Zhang Hui min,Mechanism and Mode selection of synergy innovation for small and micro enterprises under the new normal, J of Economy and management,2016,No 5,p77-79.

[6] Yu Weizhen, Li Wenjie, Core resources, synergy innovation and the development of small and micro enterprises of science and technology, $\mathrm{J}$ of progress in Science and technology and Countermeasures,2016, No 6,p94-100.

[7] Liu Cheng, Research on Innovation model of industrial design in Small and micro enterprises, J of Shandong Industrial Technology,2016,No11.

[8] Wu Songqiang, Shen Xinyi, Shi Kuiran, Jia Liangding, Research on Synergy Innovation Strategy of small and micro enterprises under the background of transformation and upgrading, $\mathrm{J}$ of Science and technology management research,2015,No 5,p6-10.

[9] Yin Hui,Zhou Jun, Research on the development of small and micro enterprises from the perspective of Synergy Innovation, $J$ of Science and Technology Progress and Countermeasures, 2014,No 1,p108-112.

[10] Xu Li, Zhang Siqin, Zhao Jihui, Analysis of Mode and Countermeasures of Science and Technology Synergy Innovation of small and micro enterprises , J of Science Square,2014,No 3,p123-127. 